\title{
Recovery from vecuronium is delayed in patients with hypercholesterolemia
}

\author{
[La récupération d'un bloc au vécuronium est retardée en cas \\ d'bypercholestérolémie] \\ Yuhji Saitoh MD
}

Purpose: To examine the effects of hypercholesterolemia with respect to onset time and recovery from vecuronium-induced neuromuscular block.

Methods: A randomized controlled trial was undertaken in 20 adult patients with hypercholesterolemia (hypercholesterolemia group) and 20 healthy patients with normal serum cholesterolemia (control group). Following induction of anesthesia, vecuronium $0.1 \mathrm{mg} \cdot \mathrm{kg}^{-1}$ iv was administered. Onset of neuromuscular block and recovery times in the two groups were compared using supramaximal stimulation of the ulnar nerve.

Results: The supramaximal stimulating current in the hypercholesterolemia group was similar to that of the control group (38.1 \pm 15.5 vs $31.3 \pm 7.6 \mathrm{~mA}, P=0.087)$. Onset of vecuronium-induced neuromuscular block (time to loss of response to $\mathrm{TI}$ ) in the hypercholesterolemia group was similar to that observed in the control group $(243 \pm 84$ vs $249 \pm 56 \mathrm{sec}, P=$ 0.792 ). Times from vecuronium administration to the return of TI were also similar in the two groups $(29.8 \pm 9.7$ vs $25.3 \pm$ $6.8 \mathrm{~min}, P=0.099)$. However, mean times for return of T2, T3, and T4 in the hypercholesterolemia group were longer than in the control group $(44.5 \pm 14.4$ vs $34.0 \pm 8.4 \mathrm{~min}$ for $\mathrm{T} 2, \mathrm{P}=$ 0.018 ). During recovery from neuromuscular block, $\mathrm{TI} /$ control and train-of-four ratio in the hypercholesterolemia group were less than in the control group, 90-120 min and 70-120 min after vecuronium, respectively $(P<0.05)$.

Conclusion: Recovery from vecuronium-induced neuromuscular block is delayed in patients with hypercholesterolemia.

Objectif : Vérifier les effets de l'hypercholestérolémie sur le temps d'installation et la récupération du bloc neuromusculaire induit par le vécuronium.

Méthode: Une étude randomisée et contrôlée $a$ été réalisée auprès de 20 patients adultes avec cholestérolémie formant le groupe expérimental et 20 adultes sains comme témoins. Après l'induction de l'anesthésie, du vécuronium à $0, I \mathrm{mg} \cdot \mathrm{kg}^{-1}$ iv a été administré. Les temps marquant le début du bloc neuromusculaire et la récupération dans les deux groupes ont été comparés en utilisant une stimulation supramaximale du nerf cubital.

Résultats : Le courant supramaximal stimulant a été similaire dans le groupe d'hypercholestérolémie et le groupe témoin $(38, I$ $\pm 15,5$ vs $31,3 \pm 7,6 \mathrm{~mA}, P=0,087$ ). Le début du bloc (moment de la perte de réponse à $T I$ ) a été similaire dans le groupe d'hypercholestérolémie et le groupe témoin $(243 \pm 84$ vs 249 $\pm 56 \mathrm{~s}, P=0,792$ ). Le temps écoulé entre l'administration du vécuronium et le retour de la réaction à $T \mathrm{I}$ a été aussi comparable entre les groupes $(29,8 \pm 9,7$ vs $25,3 \pm 6,8 \mathrm{~min}, P=0,099)$. Les temps moyens de retour des réactions à T2, T3 et T4 ont été plus longs dans le groupe d'hypercholestérolémie (44,5 \pm 14,4vs $34,0 \pm 8,4$ min pour T2, $P=0,018$ ). Pendant la récupération, le ratio $\mathrm{Tl} /$ témoin et celui du train-de-quatre ont été plus bas dans le groupe d'hypercholestérolémie, $90-120 \mathrm{~min}$ et $70-120 \mathrm{~min}$ respectivement après l'administration du vécuronium $(P<0,05)$.

Conclusion: La récupération d'un bloc neuromusculaire induit par le vécuronium est retardée chez les patients qui présentent de l'hypercholestérolémie.

$\mathrm{P}$ REVIOUS reports have suggested an association between hypercholesterolemia and neuropathy. ${ }^{1-5}$ In patients with hypercholesterolemia, thick, irregular disrupted myelin sheaths may be observed in between normal myelinated and unmyelinated axons of motor nerves. Separation of myelin lamellae results in loss of the normal circular orientation of these axons. ${ }^{1}$ One report has shown an accumulation of granules in Schwann

From the Department of Anesthesiology, Satte General Hospital, Saitama, Japan.

Address correspondence to: Dr. Yuhji Saitoh, Department of Anesthesiology, Satte General Hospital, 4-14-24, Higashi, Satte-City,

Saitama, 340-0114, Japan. Phone: +81-480-42-1211; Fax: +81-480-43-2403; E-mail: ysz432@yahoo.co.jp

Accepted for publication October 24, 2005.

Revision accepted February 2, 2006.

Competing interests: None declared. 
cells and sural nerve axons of a hypercholesterolemic patient, thought to represent either lipid droplets or glycogen deposition. ${ }^{2}$ In the majority of nerve fibre bundles of rats receiving a hyperlipidemic diet, demyelinated zones were found. ${ }^{3}$ There is also anecdotal evidence of reduced nerve conduction velocity in a hypercholesterolemic patient. ${ }^{1}$ Skeletal muscle weakness $^{4}$ and focal mononeuropathy or generalized polyneuropathy $y^{5}$ have also been identified in patients with hypercholesterolemia.

In the presence of motor nerve fibre impairment, the supramaximal stimulating current at which the maximal response of skeletal muscle contraction can be elicited may be high, and the action of neuromuscular blocking drugs is exaggerated. ${ }^{6,7}$ However, no previous study has investigated the clinical response of neuromuscular blocking drugs in patients with hypercholesterolemia. This study was undertaken to compare the response of a supramaximal stimulating current with respect to onset time and recovery from neuromuscular blockade induced by vecuronium in hypercholesterolemic patients, as compared to healthy patients.

\section{Methods}

The protocol of this study was approved by the institutional Ethics Committee of Satte General Hospital. Written informed consent was obtained from each subject. Twenty adult patients, ASA physical status I-II, who had hypercholesterolemia (hypercholesterolemia group), and 20 adult patients, ASA I-II, with normal serum cholesterol (control group) were studied. For this study, hypercholesterolemia was defined as plasma total cholesterol $>220 \mathrm{mg} \cdot \mathrm{dl}^{-1}$. This criterion was in accordance with previous reports. ${ }^{8}{ }^{89}$ The cholesterol results were available before the surgical procedure.

The sample size requirement was based upon an ability to detect a difference $\geq 0.2$ in mean $\mathrm{Tl} /$ control or train-of-four (TOF) ratio between groups, with a standard deviation of approximately 0.2. ${ }^{6}$ Assuming an $\alpha$ of $5 \%$ and with $90 \%$ power, 18 patients per group were required. ${ }^{10}$ To take into consideration possible loss of subjects, a total of 20 hypercholesterolemic and 20 control patients were enrolled.

Eligible patients were scheduled for elective orthopedic surgery (total hip or knee replacement), ear nose and throat surgery (tympanoplasty), or ophthalmological surgery (segmental buckling or vitrectomy) under general anesthesia. The preoperative evaluation included a clinical history and examination, blood count, liver, renal and thyroid profiles, total cholesterol, fasting blood sugar, serum protein electropho- resis, urine analysis, electrocardiograph, and chest radiograph. No patient in the hypercholesterolemia group had known of his/her hypercholesterolemia before hospitalization. The diagnosis of hypercholesterolemia had been established four to 11 days before the surgical procedure, and no hypercholesterolemic patient had been treated for his/her hypercholesterolemia. No patient in either group had neuromuscular, hepatic, renal, or cardiac disorders. In addition, no patient had diabetes mellitus or was receiving any drugs known to affect the action of neuromuscular blocking drugs.

Premedication consisted of diazepam 5-10 mg po given one hour before induction of anesthesia. After arriving in the operating theatre, routine monitors were applied. In addition, two stimulating electrodes were positioned over the ulnar nerve at the wrist. Two recording electrodes were also attached over the adductor pollicis muscle. Anesthesia was induced with propofol $1.5 \mathrm{mg} \cdot \mathrm{kg}^{-1}$ and fentanyl $2 \mu \mathrm{g} \cdot \mathrm{kg}^{-1}$. After loss of the eyelid reflex, TOF stimuli were applied every $20 \mathrm{sec}$ using an electrical nerve stimulator of a neuromuscular transmission module (M-NMT Module, Datex-Ohmeda Inc., Helsinki, Finland). Four single twitch stimuli consisting of $0.2 \mathrm{msec}$ duration square-waves were delivered at $2 \mathrm{~Hz}$. The corresponding electromyographic amplitudes were quantified using the neuromuscular transmission module, and were displayed on an anesthetic monitoring system (Anaesthetic Monitoring System A/S3, DatexOhmeda Inc., Helsinki, Finland). For each patient, the monitoring system searched automatically for the stimulus current needed to achieve the maximal response of the adductor pollicis muscle. The search began with $10 \mathrm{~mA}$ single twitch stimuli of $0.2 \mathrm{msec}-$ duration applied every second. The stimulating current was increased in steps of $5 \mathrm{~mA}$ until the increase in current no longer increased the electromyographic response. The stimulating current was then automatically increased by $15 \%$, to produce a supramaximal current. If the supramaximal current was not found or the response was too weak to determine the current, the current was set at $70 \mathrm{~mA}$.

Once the supramaximal current had been established, the electromyographic amplitude of Tl was considered to be the control value. The control value was again determined ten minutes after starting TOF stimuli, which were applied every $20 \mathrm{sec}$, as recommended previously. ${ }^{11,12}$ During the stabilization of neuromuscular monitoring, the patients' lungs were ventilated using a facemask with oxygen $6 \mathrm{~L} \cdot \mathrm{min}^{-1}$ and sevoflurane $2.0 \%$ inspired concentration. After recording the control value, vecuronium $0.1 \mathrm{mg} \cdot \mathrm{kg}^{-1}$ 
TABLE I Patient characteristics of the hypercholesterolemia and control groups

\begin{tabular}{llll}
\hline & $\begin{array}{l}\text { Hypercholesterolemia } \\
(n=20)\end{array}$ & $\begin{array}{l}\text { Control } \\
(n=20)\end{array}$ & P value \\
\hline Sex (female/male) & $13 / 7$ & $13 / 7$ & \\
Age $(\mathrm{yr})$ & $61 \pm 12$ & $58 \pm 14$ & 0.490 \\
Weight $(\mathrm{kg})$ & $56 \pm 11$ & $56 \pm 9$ & 0.913 \\
Height $(\mathrm{cm})$ & $157 \pm 8$ & $156 \pm 9$ & 0.872 \\
$\begin{array}{l}\text { Total cholesterol } \\
\left(\mathrm{mg} \cdot \mathrm{dl}^{-1}\right)\end{array}$ & $246 \pm 12$ & $173 \pm 27$ & $<0.001$ \\
& & & \\
\hline
\end{tabular}

Values are number or mean \pm SD. TOF $=$ train-of-four. Sex, age, weight, and height were similar between the two groups. The value of serum total cholesterol was higher in the hypercholesterolemia group than in the control group $(P<0.001)$.

TABLE II Time from vecuronium $0.1 \mathrm{mg} \cdot \mathrm{kg}^{-1}$ to the return of $\mathrm{T} 1, \mathrm{~T} 2, \mathrm{~T} 3$, or $\mathrm{T} 4$ in the hypercholesterolemia and control groups

\begin{tabular}{llll}
\hline & $\begin{array}{l}\text { Hypercholesterolemia } \\
(n=20)\end{array}$ & $\begin{array}{l}\text { Control } \\
(n=20)\end{array}$ & P value \\
\hline T1 $(\min )$ & $29.8 \pm 9.7$ & $25.3 \pm 6.8$ & 0.099 \\
T2 $(\min )$ & $44.5 \pm 14.4$ & $34.0 \pm 8.4$ & 0.009 \\
T3 $(\min )$ & $55.0 \pm 19.4$ & $39.5 \pm 10.0$ & 0.004 \\
T4 $(\min )$ & $57.8 \pm 20.1$ & $42.0 \pm 10.6$ & 0.004 \\
\hline
\end{tabular}

Values are mean $\pm S D$. TOF $=$ train-of-four. Times to the return of Tl did not differ between the two groups. Times to the return of T2, T3, and T4 were longer in the hypercholesterolemia group than in the control group $(P<0.05)$.

was administered intravenously to facilitate tracheal intubation.

After vecuronium injection, TOF stimuli were continuously applied every $20 \mathrm{sec}$. Times from the administration of vecuronium to the onset of neuromuscular blockade (times from vecuronium to the disappearance of TOF response) were compared between groups. Also, times from vecuronium to the return of T1, T2, T3, and T4 (the first, second, third, and fourth response of the TOF) were compared between groups. After vecuronium, Tl/control was compared every ten minutes between groups. Similarly, T4/Tl (TOF ratio, TOFR) was compared every ten minutes between groups.

Anesthesia was maintained with nitrous oxide $66 \%$ in oxygen and sevoflurane $1.7 \%$ end-tidal concentration. A bolus dose of fentanyl $2 \mu \mathrm{g} \cdot \mathrm{kg}^{-1}$ in was administered before skin incision. Whenever the level of anesthesia was thought to be inadequate, a supplemental bolus of fentanyl $2 \mu \mathrm{g} \cdot \mathrm{kg}^{-1} i v$ was administered. Ventilation was controlled to maintain normocapnia $\left(\mathrm{P}_{\mathrm{ET}} \mathrm{CO}_{2}\right.$ $32-37 \mathrm{mmHg}$ ). The end-tidal concentrations of anes-

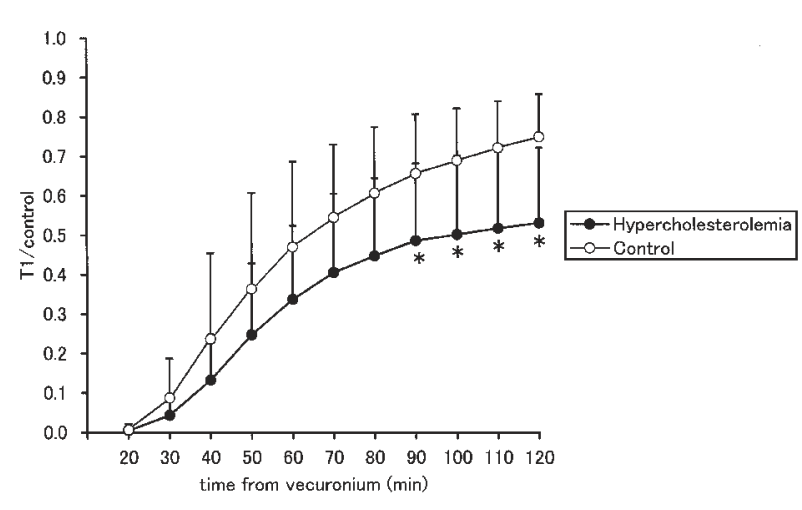

FIGURE 1 Recoveries of $\mathrm{Tl} /$ control after administration of vecuronium $0.1 \mathrm{mg} \cdot \mathrm{kg}^{-1}$ in the hypercholesterolemia ( and control $(O)$ groups. Values are mean $\pm \mathrm{SD} .{ }^{*} P<0.05$ between the two groups.

thetic and $\mathrm{P}_{\mathrm{ET}} \mathrm{CO}_{2}$ were measured continuously using a multiple gas monitor belonging to the anesthetic monitoring system. Rectal temperature was monitored throughout the surgical procedure. Also, the surface skin temperature over the adductor pollicis muscle was measured using a thermometer probe (Terumo-Finer, Terumo Inc., Tokyo, Japan).

Patient characteristics were compared using an unpaired t test or Chi-square statistic. The stimulating currents, times to onset of neuromuscular blockade, and times to the return of T1, T2, T3, or T4 were compared between groups using unpaired $\mathrm{t}$ tests. Comparison of $\mathrm{Tl} /$ control or TOFR during recovery from neuromuscular block between groups was done using analysis of variance (ANOVA) and unpaired t tests with Bonferroni's adjustment. All results are expressed as numbers or mean $\pm \mathrm{SD}$. A $P$ value < 0.05 was considered statistically significant. Statistical analyses were performed using a statistical package (SYSTAT 8.0, SPSS Inc., Chicago, IL, USA) running on a personal computer.

\section{Results}

Patient characteristics were comparable between groups (Table I). The supramaximal stimulating current in the hypercholesterolemia group did not differ from that in the control group $(38.1 \pm 15.5$ vs 31.3 $\pm 7.6 \mathrm{~mA}, P=0.087)$. Onset of neuromuscular block in the hypercholesterolemia group was similar to that in the control group $(243 \pm 84$ vs $249 \pm 56 \mathrm{sec}$, $P=0.792)$. Time from vecuronium administration to return of $\mathrm{Tl}$ was also similar in the two groups. 


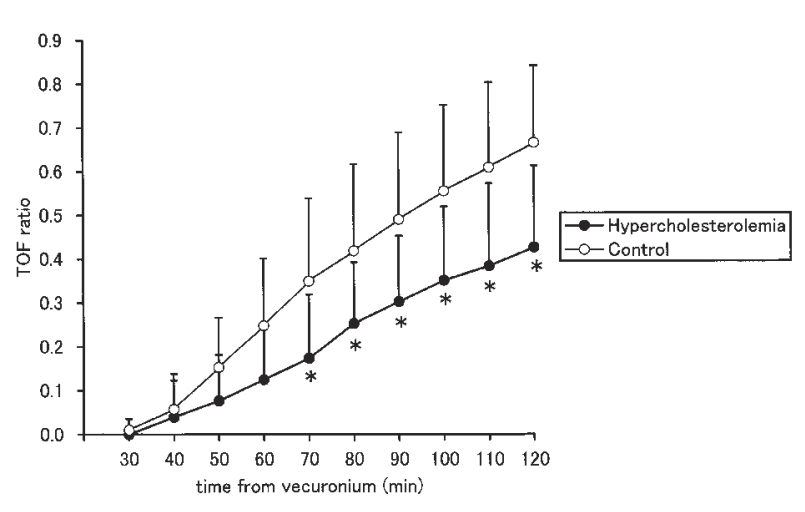

FIGURE 2 Recoveries of train-of-four ratio after administration of vecuronium $0.1 \mathrm{mg} \cdot \mathrm{kg}^{-1}$ in the hypercholesterolemia $(-)$ and control $(O)$ groups. Values are mean \pm SD. ${ }^{*} P<0.05$ between the two groups.

However, times to return of $\mathrm{T} 2, \mathrm{~T} 3$, and $\mathrm{T} 4$ in the hypercholesterolemia group were longer than in the control group $(P<0.05)$, (Table II). The Tl/control responses and TOFR in the hypercholesterolemia group were less than in the control group, 90-120 min and 70-120 min after the administration of vecuronium, respectively $(P<0.05)$, (Figures 1 and $2)$. In no patient did the rectal temperature or peripheral temperature over the adductor pollicis muscle decrease to less than $35.5^{\circ} \mathrm{C}$ or $32.0^{\circ} \mathrm{C}$, respectively.

\section{Discussion}

This study shows that the supramaximal stimulating current and onset of neuromuscular blockade caused by vecuronium do not differ between hypercholesterolemic and healthy patients. However, the times required for return of $\mathrm{T} 2, \mathrm{~T} 3$, and $\mathrm{T} 4$ are longer in the hypercholesterolemic patients compared to the healthy patients. Recovery times of $\mathrm{Tl} / \mathrm{control}$ or TOFR are slower in the hypercholesterolemic patients in comparison to the healthy patients.

To date, there has been somewhat limited evidence linking hypercholesterolemia with altered neuromuscular function. In rats fed with a hyperlipidemic diet, the majority of nerve fibre bundles show areas of demyelination, and Schwann cells contain large round dense bodies within their cytoplasm. ${ }^{3}$ In the clinical setting, Sandbank et al. ${ }^{1}$ describe a case of ulnar nerve paralysis in a patient with hypercholesterolemia. An electromyographic study of this patient's facial nerve showed increased latency and a scattered response to stimulation, while the hypothenar muscles revealed a reduced interference pattern, and a decrease in conduction velocity was observed in the tibial nerve. ${ }^{1}$ Electron microscopy revealed a very thick, irregular disrupted myelin sheath, invagination of the myelin sheath into the axon, and aggregation of lipid droplets in the axon. Within Schwann cells and axons of the sural nerve of a hypercholesterolemic patient, an accumulation of granules has been observed, which may have been either lipid droplets or glycogen. ${ }^{2}$ Bechar et al. ${ }^{4}$ reported a decrease of hand strength in a hypercholesterolemic patient. David et al. ${ }^{5}$ noted an association between hypercholesterolemia and focal mononeuropathy or generalized polyneuropathy. If motor nerve fibres are impaired, the action of neuromuscular blocking drugs is exaggerated. ${ }^{6,7}$ In patients with diabetes mellitus, demyelination is apparent in the motor nerve endings, ${ }^{13,14}$ and recovery from vecuronium-induced neuromuscular block is delayed. ${ }^{6}$ The current investigation demonstrates that the duration of neuromuscular block associated with vecuronium is prolonged in hypercholesterolemic patients. While the study did not address mechanisms, it is possible that motor nerve endings were altered or damaged in these patients.

In the present study the time to the return of $\mathrm{Tl}$ did not differ between groups, whereas recovery times of T2, T3, or T4 were longer in the hypercholesterolemia group than in the control group. These results were the same as those obtained in a previous study, ${ }^{15}$ in which recovery of TOF was examined in diabetic patients and healthy patients. When the degree of neuromuscular blockade is profound, i.e., when a response to $\mathrm{Tl}$ is barely elicited, recovery of TOF in diabetic patients and healthy patients might follow a similar time course. In contrast, as the level of neuromuscular block subsided and a response to T2, $\mathrm{T} 3$, or $\mathrm{T} 4$ became detectable, the return of $\mathrm{T} 2, \mathrm{~T} 3$, or T4 would be delayed in diabetic patients as compared with healthy subjects. ${ }^{15}$ On similar grounds, the return of T2, T3, or T4 would be delayed in hypercholesterolemic patients.

In this study, patients whose serum total cholesterol was $>220 \mathrm{mg} \cdot \mathrm{dl}^{-1}$ were assigned to the hypercholesterolemia group. However, in the clinical setting, investigations other than serum total cholesterol may be warranted. The guidelines for the management of hyperlipidemias for prevention of atherosclerosis proposed by the Japan Atherosclerosis Society (JAS) Guidelines Investigating Committee defined the diagnostic criteria for abnormalities of serum total cholesterol, low density lipoprotein (LDL)-cholesterol, high density lipoprotein (HDL)-cholesterol, and triglycerides. ${ }^{8}$ The committee also establishes target levels of 
treatment for total and LDL-cholesterol. McManis et al. ${ }^{16}$ reported that in some hypertriglyceridemic patients, compound muscle action potential amplitude decreased when assessed electromyographically. As the action of neuromuscular blocking drugs may be exaggerated in hypertriglyceridemic patients, not only serum cholesterol, but also LDL-cholesterol, HDLcholesterol, and triglyceride levels should be taken into consideration.

The diagnosis of hypercholesterolemia had been established four to 11 days before the surgical procedure in all hypercholesterolemiic patients in the current study, and none of these patients had been receiving treatment for their disorder. Bechar et al. ${ }^{4}$ reported that neuropathy associated with hypercholesterolemia develops simultaneously with the appearance of elevated serum cholesterol, and improves cholesterol values normalized in response to treatment. If the hypercholesterolemic patients had been treated for hypercholesterolemia, recovery from neuromuscular blockade might not have been delayed. However, David et al. ${ }^{5}$ reported that the degree of cholesterol elevation did not correlate with the presence or absence of neuropathy. Moreover, it has been shown that 3-hydroxy-3-methylglutaryl-coenzyme A (HMG-CoA) reductase inhibitors, which are administered for hypercholesterolemia, are associated with muscle fibre necrosis and degeneration in rabbits. ${ }^{17}$ Ucar et al. ${ }^{18}$ described in patients receiving HMGCoA reductase inhibitors, adverse reactions involving skeletal muscle, such as myopathy and rhabdomyolysis. Even though hypercholesterolemia is treated by HMG-CoA reductase inhibitors, the duration of action of vecuronium may not be normalized as the skeletal muscle is damaged. To better address these issues, further studies are needed.

Finally, as this study was performed in Japan, patients' body weight and height were smaller than expected in the Canadian population. Semple et al. ${ }^{19}$ compared the potency of vecuronium when given to anesthetized patients in Australia and the United Kingdom. They showed that the potency of vecuronium was independent of weight and height, and did not differ between patients in Australia and United Kingdom. This suggests that the difference in the action of vecuronium between patients in Canada and Japan might be trivial.

In conclusion, the supramaximal stimulating current is not different when comparing hypecholesterolemic and healthy patients. While not influencing the onset of neuromuscular block, time from administration of vecuronium to the return of T2, T3, or T4 is prolonged, and recovery of $\mathrm{Tl} / \mathrm{control}$ or TOFR values are delayed in hypercholesterolemic patients. Our findings suggest that particular care in dose titration, and enhanced vigilance in monitoring recovery of the degree of neuromuscular block are warranted in hypercholesterolemic patients receiving non-depolarizing neuromuscular blocking drugs during the conduct of general anesthesia.

\section{References}

1 Sandbank U, Bechar M, Bornstein B. Hyperlipemic polyneuropathy. Case report: histological and electronmicroscopical study. Acta Neuropathol (Berl) 1971; 19: 290-300.

2 Ibara $\Upsilon$, Nobukuni K, Namba R, et al. A family of familial hypercholesterolemia with cerebral infarction and without coronary heart disease. An unusual case with corneal opacity, polyneuropathy and carpal tunnel syndrome in the family: therapy with probucol and tocopherol nicotinate. J Neurol Sci 1991; 106: 10-8.

3 Sandbank U, Bubis JJ. Hyperlipaemic neuropathy. Experimental study. Brain 1973; 96: 355-8.

4 Bechar M, Kott E, Bornstein B. Polyneuropathy associated with hyperlipemia. Confin Neurol 1969; 31: 281-8.

5 David WS, Mahdavi Z, Nance M, Khan M. Hyperlipidemia and neuropathy. Electromyogr Clin Neurophysiol 1999; 39: 227-30.

6 Saitoh Y, Kaneda K, Hattori H, Nakajima H, Murakawa $M$. Monitoring of neuromuscular block after administration of vecuronium in patients with diabetes mellitus. Br J Anaesth 2003; 90: 480-6.

7 Savarese JJ, Caldwell JE, Lien CA, Miller RD. Pharmacology of muscle relaxants and their antagonists. In: Miller RD (Ed.) Anesthesia, 5th ed. Philadelphia: Churchill Livingstone Inc.; 2000: 471-2.

8 Hata $\Upsilon$, Mabuchi H, Saito $\Upsilon$, et al.; Working Committee on JAS Guidelines for Diagnosis and Treatment of Hyperlipidemias. Report of the Japan Atherosclerosis Society (JAS) Guideline for Diagnosis and Treatment of Hyperlipidemia in Japanese Adults. J Atheroscler Thromb 2002; 9: 1-27.

9 Muramatsu J, Kobayashi A, Hasegawa N, Yokouchi S. Hemodynamic changes associated with reduction in total cholesterol by treatment with the HMG-CoA reductase inhibitor pravastatin. Atherosclerosis 1997; 130: 179-82.

10 Browner WS, Newman TB, Cummings SR, Hulley SB. Estimating sample size and power: the nitty-gritty. In: Hiscock TY (Ed.). Designing Clinical Research. 2nd ed. Philadelphia: Lippincott Williams \& Wilkins Inc.; 2001: 65-91.

11 Viby-Mogensen J, Engbek J, Eriksson LI, et al. Good clinical research practice (GCRP) in pharmacodyna- 
mic studies of neuromuscular blocking agents. Acta Anaesthesiol Scand 1996; 40: 59-74.

12 Donati F. Onset of action of relaxants. Can J Anaesth 1988; 35: S52-8.

13 Lawrence DG, Locke S. Motor nerve conduction velocity in diabetes. Arch Neurol 1961; 5: 483-9.

14 Abu-Shakra SR, Cornblath DR, Avila OL, et al. Conduction block in diabetic neuropathy. Muscle \& Nerve 1991; 14: 858-62.

15 Saitoh $\Upsilon$, Hattori H, Sanbe N, Nakajima H, Akatu M, Murakawa $M$. Delayed recovery of vecuronium neuromuscular block in diabetic patients during sevoflurane anesthesia. Can J Anesth 2005; 52: 467-73.

16 McManis PG, Windebank AJ, Kiziltan M. Neuropathy associated with hyperlipidemia. Neurology 1994; 44: 2185-6.

17 Nakahara K, Kuriyama M, Sonoda , et al. Myopathy induced by HMG-CoA reductase inhibitors in rabbits: a pathological, electrophysiological, and biochemical study. Toxicol Appl Pharmacol 1998; 152: 99-106.

18 Ucar M, Mjörndal T, Dablqvist R. HMG-CoA reductase inhibitors and myotoxicity. Drug Saf 2000; 22: 441-57.

19 Semple P, Hope DA, Cryburn P, Rodbert A. Relative potency of vecuronium in male and female patients in Britain and Australia. Br J Anaesth 1994; 72: 190-4. 